\title{
Clinical outcomes of patients with primary malignant bone and soft tissue tumor aged 65 years or older
}

\author{
KAZUHIKO HASHIMOTO, SHUNJI NISHIMURA, YUKIKO HARA, NAOHIRO OKA, \\ HIROKI TANAKA, SHUNKI IEMURA and MASAO AKAGI
}

Department of Orthopedic Surgery, Kindai University Hospital, Osaka-Sayama, Osaka 589-8511, Japan

Received June 14, 2018; Accepted November 11, 2018

DOI: $10.3892 /$ etm.2018.7013

\begin{abstract}
The number of elderly patients with sarcoma (65 years or older) has increased with the rise in the aging of society. As it is difficult to treat elderly sarcoma patients in the same manner as younger patients, the present study sought to compare treatment options currently available for elderly patients. The present study was comprised 34 Japanese patients ( 21 men and 13 women) with malignant bone or soft tissue tumors who underwent surgery in our department from September 2004 to March 2014. The median patient age was 72 years (range, 65-86 years). Histologically, 23 cases were categorized as high-grade and 11 as low-grade. Treatments included surgery with adequate margins (25 cases), surgery with inadequate margins and radiotherapy (4 cases), surgery with inadequate margins and chemotherapy (3 cases) and intralesional resection ( 2 cases). The postoperative follow-up period ranged from 7 to 112 months (average, 49 months). The 5 -year survival rates were determined and compared using the Kaplan-Meier method and log-rank test, respectively. Eastern Cooperative Oncology Group Performance Status (ECOG-PS) and Anesthesiologists-Physical Status (ASA-PS) scores were also determined. The overall 5-year survival rate was $86.02 \%$; it differed significantly between patients with high-grade $(100 \%)$ vs. low-grade $(74.3 \%)$ neoplasms $\mathrm{P}<0.001)$, but not between patients aged 65-69 (76.9\%) vs. $\geq 70(90.2 \%)$ years-old $(\mathrm{P}=0.65)$. Tumor status was classified as follows: i) Continuously disease-free, $n=24$ cases; ii) alive with disease, $n=3$ cases; iii) and dead of disease, $n=7$ cases. The ECOG-PS status scores were 0 in 9 cases, 1 in 21 cases, and 2 in 4 cases. ASA-PS scores were also I in 9 cases and II in 23 cases. Thus, the primary treatment for elderly patients with sarcoma should be surgery alone
\end{abstract}

Correspondence to: Dr Kazuhiko Hashimoto, Department of Orthopedic Surgery, Kindai University Hospital, 377-2 Ohno-Higashi, Osaka-Sayama, Osaka 589-8511, Japan

E-mail: hazzhiko@med.kindai.ac.jp

Abbreviations: ASA-PS, Anesthesiologists-Physical Status; ECOG-PS, Eastern Cooperative Oncology Group Performance Status

Key words: sarcoma, elderly, treatment strategy as no additional benefits were obtained when radiotherapy or chemotherapy was also performed. Adequate margins should be confirmed along with the histology of surgical specimens.

\section{Introduction}

The aging of the Japanese population is currently unprecedented (1). The percentage of the population aged 65 years or older in 2017 was $27.3 \%$ according to a report from the Japanese cabinet (2). The incidence of sarcoma increases progressively with age (3), and the number of sarcoma patients in Japan increases yearly according to the Japanese Registry of Musculoskeletal Oncology (4).

At present, there are no established treatments for elderly sarcoma patients, who are difficult to treat in the same manner as their young counterparts because of potential immunodeficiencies, underlying diseases, complications, and social backgrounds. Moreover, studies addressing the management of elderly sarcoma patients are few (4-10), with controversial results. Here we present a retrospective study aimed at determining the best treatment strategy for elderly sarcoma patients.

\section{Materials and methods}

Patients and treatments. The present retrospective study comprised 34 patients (21 men and 13 women) with malignant bone or soft tissue tumors who underwent surgery in our department from September 2004 to March 2014 (Table I). The median patient age was 72 years (range, 65-86 years); 11 patients were 65-69 years-old, 10 were $70-74$ years-old, and 13 were $\geq 75$ years-old. All patients provided written informed consent for this retrospective study.

The tumor sites were the legs (28 cases), arms (3 cases), and trunk (3 cases) (Table I). The histological tumor types were liposarcoma (19 cases), leiomyosarcoma (9 cases), undifferentiated pleomorphic sarcoma (3 cases), chondrosarcoma (2 cases), and synovial sarcoma (1 case). Among the 19 liposarcoma cases, 3 were well differentiated, 4 were dedifferentiated, 2 were myxoid, and 10 were pleomorphic (11).

The classification systems of the French Federation of Comprehensive Cancer Centers (12) and Lee et al (13) were used for histological grading of soft tissue and bone sarcomas, respectively. Twenty-three sarcomas were categorized as high-grade and 11 as low-grade (Table I). Eleven soft tumor 
Table I. Characteristics of the study population.

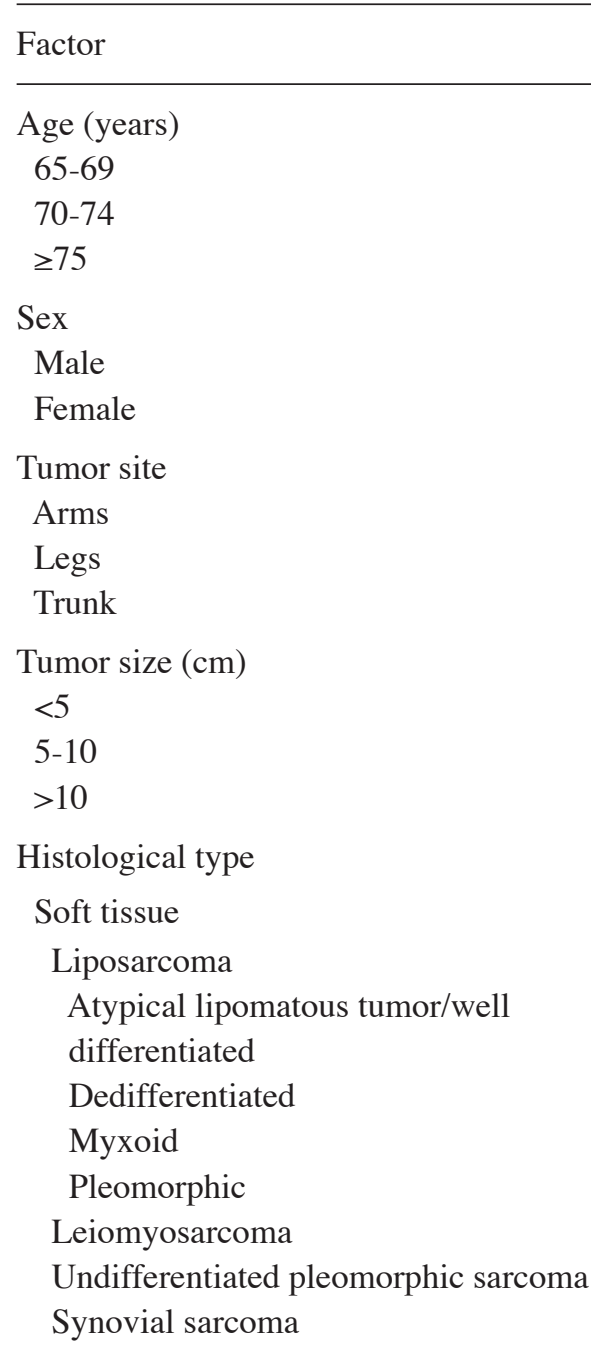

Bone

Chondrosarcoma

Histological grade

Total

Low

High

Bone tumor

Grade 1

Grade 2

Grade 3

Soft tissue (FNCLCC grading system)

Grade 1

Grade 2

Grade 3

Complications

Diabetes mellitus

Hypertension

Dementia

Hepatitis

$19(56)$

$3(9)$

4 (12)

2 (6)

10 (29)

9 (26)

3 (9)

1 (3)

$2(6)$

$11(32)$

23 (68)

$0(0)$

$1(3)$

$1(3)$

11 (32)

3 (9)

18 (53)

Metastasis at initial visit

$(-)$

(+)
Table I. Continued.

Factor

Patients, n (\%)

Surgical margin

R0

25 (74)

R1

7 (20)

2 (6)

Adequate

25 (74)

Inadequate

7 (20)

Intralegional

2 (6)

Surgical time (min)

$<60$

4 (12)

60-120

$>120$

19 (56)

$11(32)$

Blood loss (cc)

$<100$

$20(59)$

100-200

6 (17)

5 (15)

3 (9)

3 (9)

$>400$

30 (88)

Adjuvant radiotherapy

4 (12)

(+)

Adjuvant chemotherapy

$(-)$

31 (91)

(+)

Follow-up period (years)

$<5$

$11(32)$

$\geq 5$

23 (68)

Oncological result

CDF

24 (71)

AWD

DOD

7 (20)

Recurrence

(-)

20 (59)

(+)

10 (41)

\section{ECOG-PS}

$$
0
$$

21 (62)

4 (12)

$0(0)$

$0(0)$

ASA-PS

I

9 (26)

23 (74)

$0(0)$

0 (0)

0 (0)

0 (0)

VI

FNCLCC, French Federation of Comprehensive Cancer Centers; $\mathrm{CDF}$, continuous disease-free; AWD, alive with disease; DOD, dead of disease; ECOG-PS, Eastern Cooperative Oncology Group Performance Status; ASA-PS, Anesthesiologists-Physical Status. 
sarcomas were grade 1; 3 were grade 2; and 18 were grade 3 . One chondrosarcoma was grade 2 and the other was grade 3. The complications were diabetes mellitus (5 cases), hypertension (15 cases), dementia ( 2 cases), and hepatitis ( 1 case). Three patients had metastatic lesions at their first visit.

Treatments included surgery with adequate margins (25 cases), surgery with inadequate margins and radiotherapy (4 cases), surgery with inadequate margins and chemotherapy ( 3 cases), and intralesional resection ( 2 cases). The postoperative observation period ranged from 7 to 112 months (average, 49 months).

Surgery aimed to obtain adequate surgical margins in all cases. Using previously described methods, surgical margins were classified as adequate, inadequate, or intralesional (14) and R0, R1, or R2 (15). R1 and R2 margins are those in which residual tumor is detectable microscopically and macroscopically, respectively. R0 margins are tumor-free (15). The margins were inadequate in cases where the tumors were intensive. These tumors were treated via marginal resection because aggressive surgery may have impaired performance status. Twenty-five (74\%) cases were R0, 7 (20\%) were R1, and $2(6 \%)$ were R2 (Table I). The mean surgical time was $114.7 \mathrm{~min}$ (range, 50-465 min), with 23 (68\%) surgeries requiring $<120 \mathrm{~min}$. The mean amount of blood loss was $160.7 \mathrm{cc}$ (range, $10-1501 \mathrm{cc})$; most patients $(31,91 \%)$ lost <300 cc.

The indication for radiotherapy was a high risk of recurrence after surgery with inadequate margins. Two patients with dedifferentiated liposarcoma, 1 patient with leiomyosarcoma, and 1 patient with pleomorphic liposarcoma received postoperative radiotherapy. A total dose of $60 \mathrm{~Gy}$ (2 Gy/day, 5 days/week) was applied to the operative field.

Systemic chemotherapy was administered to patients $<70$ years-old with preoperative metastasis or a locally intensive tumor [Eastern Cooperative Oncology Group Performance Status (ECOG-PS) score, 0-1]. Three patients with chondrosarcoma, synovial sarcoma, and dedifferentiated liposarcoma, respectively, received chemotherapy. In accordance with the Neoadjuvant Chemotherapy for Osteosarcoma protocol in Japan (95 J, 80\% dose) (16), the preoperative regimen for chondrosarcoma consisted of $8 \mathrm{~g} / \mathrm{m}^{2}$ high-dose methotrexate, $80 \mathrm{mg} / \mathrm{m}^{2}$ cisplatin, and $48 \mathrm{mg} / \mathrm{m}^{2}$ adriamycin; the postoperative regimen, which was administered to 1 patient owing to a poor response, was the same with the addition of $14 \mathrm{mg} / \mathrm{m}^{2}$ ifosfamide (16). The preoperative and postoperative (the dedifferentiated liposarcoma only) regimen for the soft tissue sarcomas consisted of 1-3 cycles of $60-75 \mathrm{mg} / \mathrm{m}^{2}$ doxorubicin, $4-5 \mathrm{mg} / \mathrm{m}^{2}$ ifosfamide, and lenograstim $(100 \mu \mathrm{g})$ every 3 weeks (17). Toxic effects were assessed using the National Cancer Institute common toxicity criteria (version 1) (17).

Statistical analysis. The 5-year survival rate was determined using the Kaplan-Meier method, and differences were assessed using the log-rank test, and $\mathrm{P}<0.05$ was considered to indicate a statistically significant difference. Statistical analysis was performed with Stat Mate (Atms, Tokyo, Japan) software for Windows, version 4.01. Recurrence rates, metastasis, ECOG-PS (18), and ASA-PS (19) were also examined. We compared the outcomes in all cases to determine the best treatment strategy for elderly sarcoma patients.
Table II. Chemotherapy-associated toxicities.

\begin{tabular}{|c|c|c|c|c|c|}
\hline \multirow[b]{2}{*}{ Toxicity } & \multicolumn{4}{|c|}{ Grade } & \\
\hline & 0 & 1 & 2 & 3 & \\
\hline \multicolumn{5}{|l|}{ Hematological, n } & \\
\hline Hemoglobin & 2 & 1 & 0 & 0 & \\
\hline White blood cells & 0 & 1 & 2 & 0 & ( \\
\hline Neutrophils & 0 & 1 & 0 & 0 & ( \\
\hline Platelets & 1 & 2 & 0 & 0 & ( \\
\hline \multicolumn{5}{|l|}{ Biochemical, $\mathrm{n}$} & \\
\hline $\mathrm{AST}$ & 2 & 1 & 0 & 0 & \\
\hline ALT & 2 & 1 & 0 & 0 & 0 \\
\hline Creatinine & 3 & 0 & 0 & 0 & \\
\hline Bilirubin & 3 & 0 & 0 & 0 & \\
\hline \multicolumn{5}{|l|}{ Clinical, $\mathrm{n}$} & \\
\hline Nausea & 2 & 1 & 0 & 0 & \\
\hline Vomiting & 1 & 0 & 0 & 0 & \\
\hline Diarrhea & 0 & 0 & 0 & 0 & \\
\hline Alopecia & 2 & 1 & 0 & 0 & \\
\hline Mucositis & 1 & 0 & 0 & 0 & \\
\hline Infection & 0 & 0 & 0 & 0 & \\
\hline Fever & 2 & 1 & 0 & 0 & \\
\hline Neurological & 0 & 0 & 0 & 0 & \\
\hline Cardiac & 0 & 0 & 0 & 0 & \\
\hline
\end{tabular}

The numbers indicate the number of patients. AST, aspartate amino transferase; ALT, alanine aminotransferase.

\section{Results}

The 5-year overall survival rate for the patients in this study was $86.02 \%$ (Fig. 1). It did not differ significantly in patients 65-69 (76.9\%) vs. $\geq 70(90.2 \%)$ years-old ( $\mathrm{P}=0.65)$ (Fig. 2$)$, but was significantly higher in those with low-grade $(100 \%)$ vs. high-grade $(74.3 \%)$ neoplasms $(\mathrm{P}<0.001)$ (Fig. 3).

Tumor status was classified as continuously disease-free (CDF) in 24 cases, alive with disease (AWD) in 3 cases, and dead of disease (DOD) in 7 cases (Table I). Tumor status according to treatment was as follows: i) Surgery with adequate surgical margins: CDF, 20 cases; AWD, 2 cases; and DOD, 3 cases; ii) surgery with inadequate margins and radiotherapy: CDF, 1 case; AWD, 1 case and DOD, 2 cases; iii) surgery with inadequate margins and chemotherapy: $\mathrm{CDF}$, 1 case and DOD, 2 cases; and iv) surgery with intralesional margins: CDF, 2 cases (Fig. 4). After these treatments, tumors recurred in $4 / 25$ cases (16\%), 3/4 cases (75\%), 2/3 cases (67\%), and $1 / 2$ cases $(50 \%)$, respectively. The recurrence rate was significantly lower in cases with adequate margins (4/25, $16 \%$ ) than in cases with inadequate margins $(6 / 9,67 \%)$ (odds ratio, 0.24; Fisher's exact test). Seven of the 10 recurrences were localized, whereas 3 metastasized to the lung. The mean time before recurrence was 10.3 months (range, 3-21 months). All metastatic lesions present at the initial visit were also present after surgery, with 1 increasing in size. 


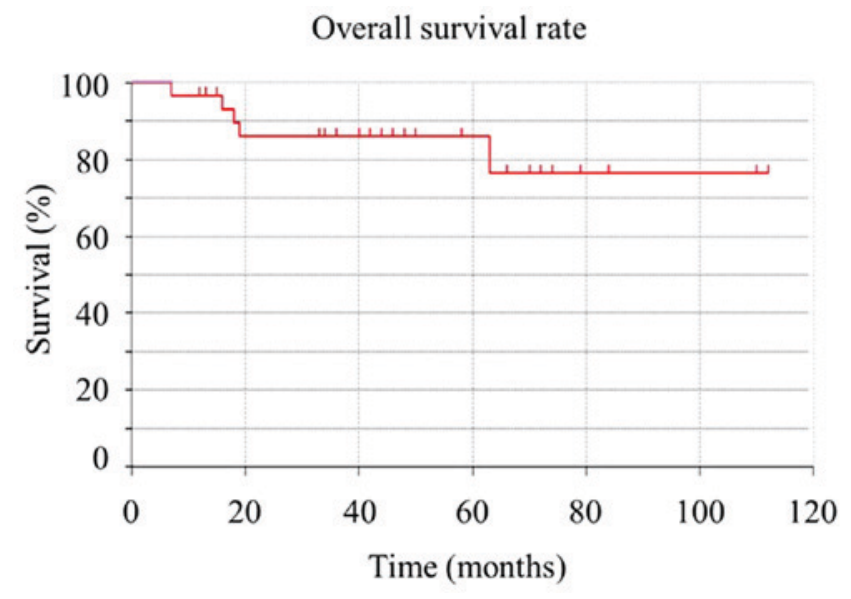

Figure 1. Survival rates of the 34 patients with malignant bone or soft tissue tumors. The Kaplan-Meier method was used to generate survival curves.

\section{Overall survival rate}

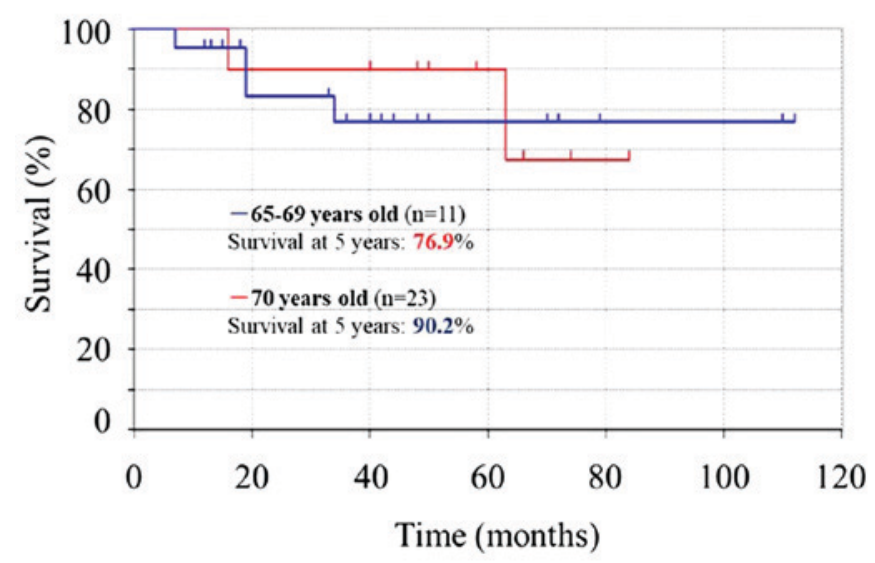

Figure 2. Prognosis according to age. The Kaplan-Meier method was used to generate survival curves. The blue line represents the data for patients 65-69 years old $(n=11)$. The red line represents the data for patients $\geq 70$ years old $(n=23)$.

\section{Overall survival rate}

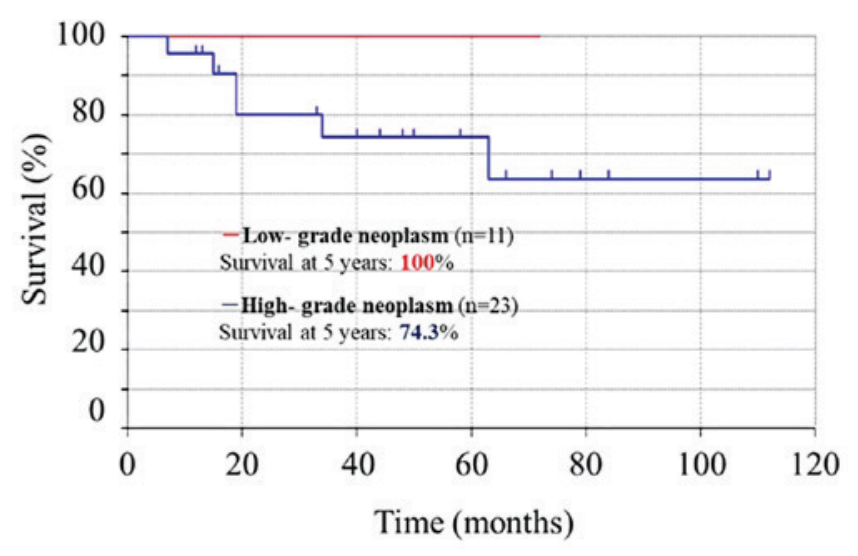

Figure 3. Prognosis according to tumor grade. The Kaplan-Meier method was used to generate survival curves. The red line represents the data for low-grade neoplasms $(\mathrm{n}=11)$. The blue line represents the data for high-grade neoplasms $(n=23)$.

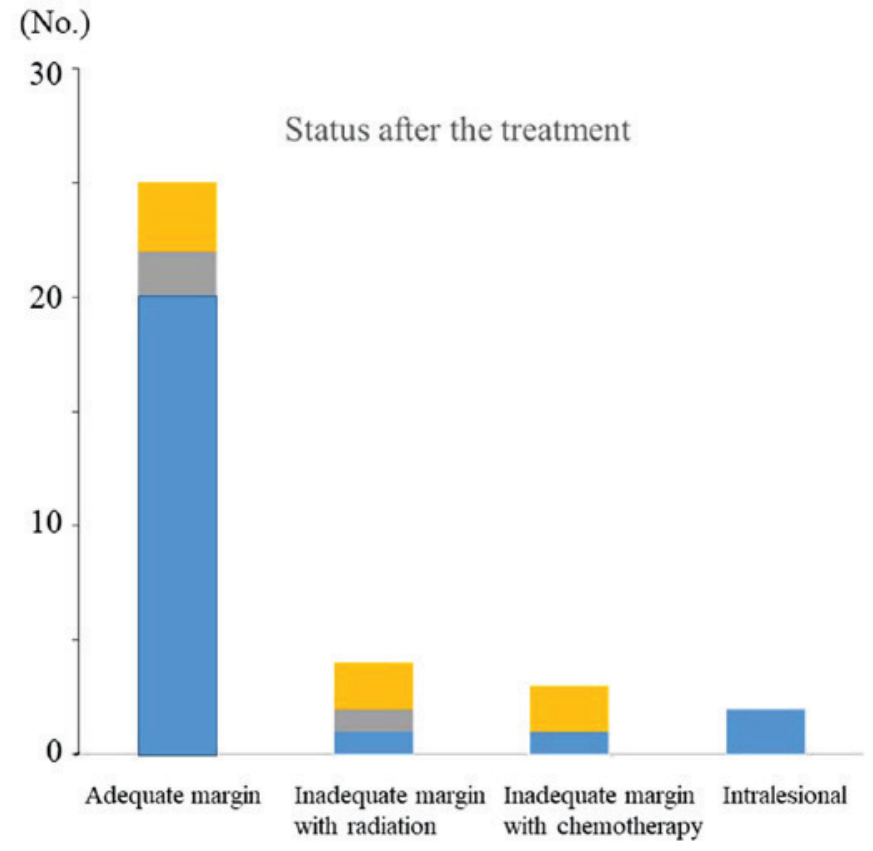

Continuous of disease free

Alive with disease

Dead of disease

Figure 4. Tumor status following treatment. The treatments included the following: Surgery with adequate margins, surgery with inadequate margins and radiotherapy, surgery with inadequate margins and chemotherapy, and intralesional resection. Tumor status was classified as continuously disease-free (blue), alive with disease (gray), or dead of disease (yellow).

Adverse events due to radiotherapy included lymphedema, which occurred in 2 patients 6-12 months after the therapy. Hematological and biological grade 0-2 adverse events were observed during chemotherapy (Table II).

The preoperative ECOG-PS scores were 0 in 9 cases, 1 in 21 cases, and 2 in 4 cases (Table I). They were unchanged after treatment. The preoperative ASA-PS scores were also I in 9 cases, and II in 23 cases (Table I).

\section{Discussion}

In general, almostall sarcoma patients are 40-60years-old $(3,12)$. However, the number of patients at the upper end of this range is increasing (12). In the present study, the outcome for sarcoma patients aged 65 years or older was almost always favorable. Most patients in the study received surgery with adequate margins (25/34), and such treatment may be necessary for a good outcome.

In our study, the 5-year overall survival rate for elderly patients with primary malignant bone or soft tissue tumors was $86.02 \%$, which is higher than previously reported rates (35.0-83.0\%, Table III) (4-10). This may reflect our more frequent achievement of adequate margins $(73.5 \%$ of cases) (6,8-10) and much lower ECOG-PS and ASA-PS scores $(6,9,10)$.

The tumor subtypes in our study are similar to those in a previous study of all age groups (20), as are the tumor sites (mainly in the limbs, with a minority in the head, neck, 


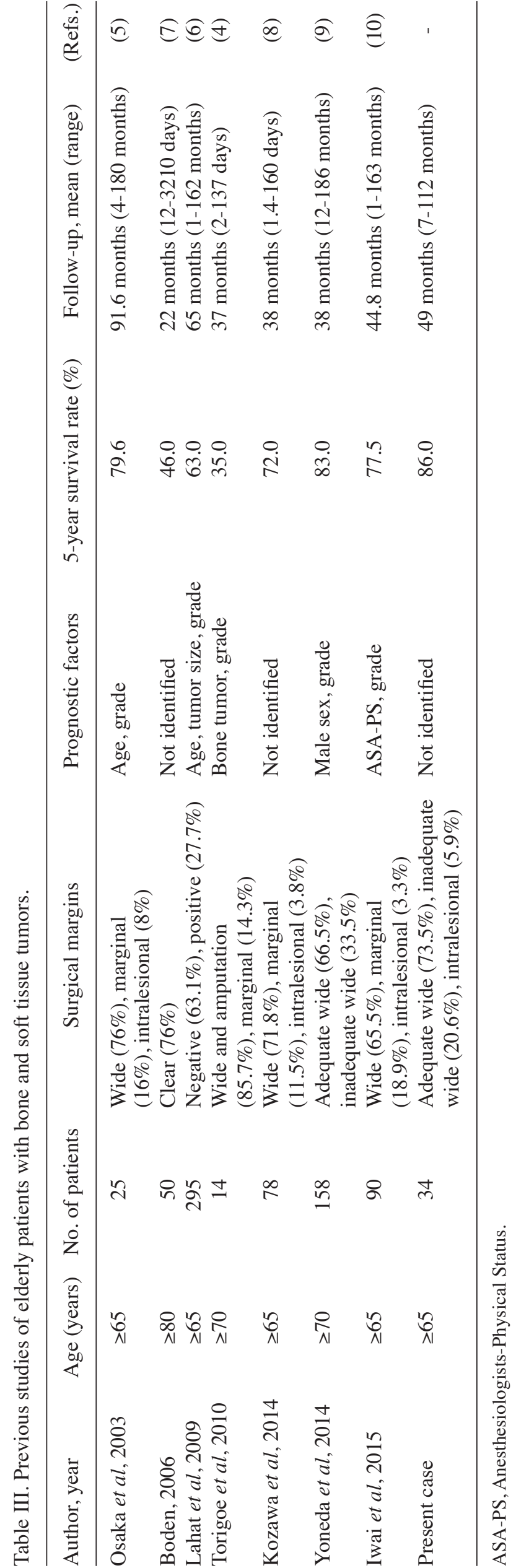

and trunk) (21). When age-matched cohorts are compared, the percentage of high-grade tumors is higher in our study (68\%) than a previous study (32\%) (22). Although 68\% of our cases had complications preoperatively, all cases were amenable to surgical treatment, with no reductions in both ECOG-PS and ASA-PS scores or worsening of complications postoperatively.

Previously, it had been reported that 5-year survival rates for elderly sarcoma patients ranged from $35.0-83.0 \%$ (4-10), with various studies suggesting that 5 -year survival rates were worse in older than in younger patients $(5,6)$. One study, for example, reported 5 -year survival rates of 46 and $63 \%$ for older and younger patients, respectively (22). In the present study, the 5-year survival rate for elderly sarcoma patients was $86.02 \%$, which is better than previously reported rates for older patients (70\%) (23) and is like that for younger patients (89.59\%) (24). These findings suggest that age itself may not affect survival of sarcoma patients.

As shown here and in previous studies, elderly patients with high-grade sarcomas have a poorer prognosis than those with low-grade sarcomas $(4,5,10)$. Hence, the histological grade of the sarcoma appears to affect the prognosis of elderly patients. Others reported a local recurrence rate of $9 \%$ at the 20-month follow-up in elderly sarcoma patients (9), as well as a local recurrence rate of $22 \%$ at the 22-month follow-up in sarcoma patients 80 years or older (7). Therefore, the recurrence rate may be somewhat worse in older (22\%) than younger sarcoma patients $(9 \%)(7,9)$.

Achieving adequate surgical margins is an important component in sarcoma treatment for elderly patients, as shown both here and by others $(5,6,9)$. The surgical resection protocol is very similar for older and younger sarcoma patients, whereas the use of adjuvant radiotherapy may differ. As a general policy, our unit recommends radiotherapy for all patients with large high-grade tumors or intermediate- or high-grade tumors of any size where the wide margin is not clear. However, when dealing with very elderly patients, additional considerations are warranted. A previous report suggests that outpatient radiotherapy is too burdensome for elderly sarcoma patients (7). In the present study, we administered radiotherapy to 4 elderly sarcoma patients as an in-hospital treatment. Although their physical status did not decline, the efficacy of this treatment could not be confirmed.

According to the European Society for Medical Oncology Guidelines (25), adjuvant chemotherapy may delay or reduce the incidence of distant and local recurrence in high-risk sarcoma patients. In elderly patients with high-grade malignant bone tumors, the use of chemotherapy is controversial. Adriamycin and ifosfamide are the main chemotherapy drugs for sarcoma (26). Since systemic chemotherapy may impair cardiac and renal function in elderly sarcoma patients $(27,28)$, it should be limited to those patients without health problems. None of the 3 patients in our study who received chemotherapy appeared to benefit from the therapy. Chemotherapy did not worsen physical function in the others. Regardless of whether it is low-dose $(80 \%)$ or high-dose, chemotherapy should be carefully administered to patients selected on the basis of age and ECOG-PS.

Patient status is mainly evaluated by determining ECOG-PS and ASA-PS scores $(18,19)$. ECOG-PS is based 
on the patient's daily activities (18), whereas ASA-PS is based on the patient's medical condition (mainly the presence or absence of systemic diseases) (19). Both systems were useful for avoiding excessive treatment of the elderly sarcoma patients in our study. ASA-PS is a potential prognostic factor for elderly sarcoma patients (10). Whether ECOG-PS is also predictive is not known and should be addressed in the future. We were unable to do so in the present study, since we did not review the patients with poor ECOG-PS scores ( $\geq 3$ ). Studies focusing on elderly sarcoma patients with poor ECOG-PS or ASA-PS $(\geq 3)$ scores are needed.

Our study has some limitations. First, there was potential selection bias since not all elderly patients are good candidates for surgery. Second, the number of patients in our study was low. The low number did not, however, preclude statistical analysis of the data. Third, our study included only 2 cases of malignant bone tumors. Fourth, we included well-differentiated liposarcomas, which are currently classified as intermediate tumors by the World Health Organization (29). However, at the time their treatment (2004-2012), they were classified as malignant tumors.

Our results suggest that surgery with adequate margins improves the prognosis of sarcoma patients 65 years-old. However, further study is required to clarify the indications for chemotherapy and radiotherapy in the elderly.

\section{Acknowledgements}

Not applicable.

\section{Funding}

No funding was received.

\section{Availability of data and materials}

The datasets used and/or analyzed during the present study are available from the corresponding author on reasonable request.

\section{Authors' contributions}

$\mathrm{KH}, \mathrm{SN}, \mathrm{YH}, \mathrm{NO}, \mathrm{HT}$, SI and MA performed the study, and collated, analyzed and interpreted the data. $\mathrm{KH}, \mathrm{SN}$, and MA wrote the manuscript.

\section{Ethics approval and consent to participate}

All patients provided written informed consent for this retrospective study.

\section{Patient consent for publication}

All patients provided written informed consent for the publication of this retrospective study.

\section{Competing interests}

The authors declare that they have no competing interests.

\section{References}

1. Montgomery W, Ueda K, Jorgensen M, Stathis S, Cheng Y and Nakamura T: Epidemiology, associated burden, and current clinical practice for the diagnosis and management of Alzheimer's disease in Japan. Clinicoecon Outcomes Res 10: 13-28, 2017.

2. Cabinet office, Government of Japan: Wite paper on aged society. http://www8.cao.go.jp/kourei/whitepaper/w-2017/zenbun/29pdf_ index.html. Accessed September, 4, 2018.

3. Balducci L and Erchler WB: Cancer and aging: A nexus at several levels. Nat Rev Cancer 5: 655-662, 2005.

4. Torigoe T, Terakado A, Suehara Y, Kurosawa H, Yazawa Y and Takagi T: Bone versus soft-tissue sarcomas in the elderly. J Orthop Surg 18: 58-62, 2010.

5. Osaka S, Sugita H, Osaka E, Yoshida Y and Ryu J: Surgical management of malignant soft tissue tumours in patients aged 65 years or older. J Orthop Surg 11: 28-33, 2003.

6. Lahat G, Dhuka AR, Lahat S, Lazar AJ, Lewis VO, Lin PP, Feig B, Cormier JN, Hunt KK, Pisters PW, et al: Complete soft tissue sarcoma resection is a viable treatment option for select elderly patients. Ann Surg Oncol 16: 2579-2586, 2009.

7. Boden RA, Clark MA, Neuhaus SJ, A'hern JR, Thomas JM and Hayes AJ: Surgical management of soft tissue sarcoma in patients over 80 years. Eur J Surg Oncol 32: 1154-1158, 2006.

8. Kozawa E, Sugiura H,Tsukushi S, Urakawa H,Arai E, FutamuraN, Nakashima H, Yamada Y, Ishiguro N and Nishida Y: Multiple primary malignancies in elderly patients with high-grade soft tissue sarcoma. Int J Clin Oncol 19: 384-390, 2014.

9. Yoneda Y, Kunisada T, Naka N, Nishida Y, Kawai A, Morii T, Takeda K, Hasei, J Yamakawa Y and Ozaki T; Japanese Musculoskeletal Oncology Group: Favorable outcome after complete resection in elderly soft tissue sarcoma patients: Japanese musculoskeletal oncology group study. Eur J Surg Oncol 40: 49-54, 2014

10. Iwai T, Hoshi M, Takada J, Oebisu N, Aono M, Takami M, Ieguchi $\mathrm{M}$ and Nakamura $\mathrm{H}$ : Prognostic factors for elderly patients with primary malignant bone and soft tissue tumors. Oncol Lett 10: 1799-1804, 2015.

11. Fletcher CD (eds), Unni KK and Mertens F: World Health Organization Classification of Tumors. Pathology and Genetics of Tumors of Soft Tissue and Bone. Rydholm A, Singer S, Sundaram M and Coinche JM (eds). IARC Press, Lyon, 12-18: 2002.

12. Weiss SW and Goldblum JR: Enzinger and Weiss's Soft Tissue Tumors. Folpe AL (eds). 4th edition. Mosby, St. Louis, MO, 1-10: 2001.

13. Lee FY, Mankin HJ, Fondren G, Gebhardt MC, Springfield DS, Rosenberg AE and Jennings LC: Chondrosarcoma of bone: An assessment of outcome. J Bone Joint Surg Am 81: 326-338, 1999.

14. Kawaguchi N, Ahmed AR, Matsumoto S, Manabe J and Matsushita Y: The concept of curative margin in surgery for bone and soft tissue sarcoma. Clin Orthop Relat Res 419: 165-172. 2004.

15. Gundle KR, Kafchinski L, Gupta S, Griffin AM, Dickson BC, Chung PW, Catton CN, O'Sullivan B, Wunder JS and Ferguson PC: Analysis of margin classification systems for assessing the risk of local recurrence after soft tissue sarcoma resection. J Clin Oncol 36: 704-709, 2018

16. Iwamoto $\mathrm{Y}$, Tanaka K, Isu K, Kawai A, Tatezaki S, Ishii T, Kushida K, Beppu Y, Usui M, Tateishi A, et al: Multiinstitutional phase II study of neoadjuvant chemotherapy for osteosarcoma (NECO study) in Japan: NECO-93J and NECO-95J. J Orthop Sci 14: 397-404, 2009.

17. Woll PJ, Reichardt P, Le Cesne A, Bonvalot S, Azzarelli A, Hoekstra HJ, Leahy M, Van Coevorden F, Verweij J, Hogendoorn PC, et al: Adjuvant chemotherapy with doxorubicin, ifosfamide, and lenograstim for resected soft-tissue sarcoma (EORTC 62931): A multicentre randomised controlled trial. Lancet Oncol 13: 1045-1054, 2012.

18. Oken MM, Creech RH, Tormey DC, Horton J, Davis TE, McFadden ET and Carbone PP: Toxicity and response criteria of the Eastern Cooperative Oncology Group. Am J Clin Oncol 5: 649-655, 1982.

19. Hosking MP, Warner MA, Lobdell CM, Offord KP and Melton LJ III: Outcomes of surgery in patients 90 years of age and older. JAMA 261: 1909-1915, 1989.

20. Pitcher ME, Fish S and Thomas JM: Management of soft tissue sarcoma. Br J Surg 81: 1136-1139, 1994. 
21. Clark MA, Fisher C, Judson I and Thomas JM: Soft-tissue sarcomas in adults. N Engl J Med 353: 701-711, 2005.

22. Ramanathan RC, A'Hern R, Fisher C and Thomas JM: Prognostic index for extremity soft tissue sarcoma with isolated local recurrence. Ann Surg Oncol 8: 278-289, 2001.

23. Harrison DJ, Geller DS, Gill JD, Lewis VO and Gorlicl R: Current and future therapeutic approaches for osteosarcoma. Expert Rev Anticancer Ther 18: 39-50, 2018.

24. Hager S, Makowiec F, Henne K, Hopt UT and Wittel UA Significant benefits in survival by the use of surgery combined with radiotherapy for retroperitoneal soft tissue sarcoma. Radiat Oncol 12: 29, 2017.

25. ESMO/European Sarcoma Network Working Group: Soft tissue, visceral sarcomas: ESMO clinical practice guidelines for diagnosis, treatment and follow-up. Ann Oncol 23 (Suppl 7): vii92-vii99, 2012.
26. Linch M, Miah AB, Thway K, Judson IR and Benson C: Systemic treatment of soft-tissue sarcoma-gold standard and novel therapies. Nat Rev Clin Oncol 11: 187-202, 2014

27. Farry JK, Flombaum CD and Latcha S: Long term renal toxicity of ifosfamide in adult patients-5 year data. Eur J Cancer 48: 1326-1331, 2012

28. Matushansky I, Dela Cruz F, Insel BJ, Hershman DL and Neugut AI: Chemotherapy use in elderly patients with soft tissue sarcoma: A population-based study. Cancer Invest 31: 83-91, 2013.

29. Fletcher CD, Bridge JA, Hogendoom PC and Mertens F: WHO Classification of Tumors of Soft Tissue and Bone. Mertens F (eds). 4th edition. IARC Publications, France, 5: 33-38, 2013. 